\title{
1 Cytolysin-positive Enterococcus faecalis is elevated in patients with chronic alcoholic
}

\section{pancreatitis}

3 Clara Perrin ${ }^{1}$, Vinciane Rebours ${ }^{2,3}$, Nicolas Trainel $^{1}$, Cosmin Sebastian Voican ${ }^{1,4}$, Gabriel

4 Perlemuter $^{1,4}$, Anne-Marie Cassard ${ }^{1 *}$, and Dragos Ciocan ${ }^{1,4^{*}}$

5

$6{ }^{*}$ Corresponding authors:

7 Dragos Ciocan: Hôpital Antoine-Béclère, Hepato-Gastroenterology and Nutrition, 157 rue de

8 la porte de Trivaux, 92140 Clamart, France.Tel: +331453743 71, Fax: +331453740 44,

9 dragosmarius.ciocan@aphp.fr

10 Anne-Marie Cassard: INSERM U996, 32 rue des carnets 92190 Clamart, France. Tel: +33 1

11412880 37, Fax: +33 1463279 93, cassard.doulcier@u-psud.fr

12

13 Univ. Paris-Saclay, Inserm U996, Inflammation, Microbiome and Immunosurveillance, 1492140 , Clamart, France

$15{ }^{2}$ INSERM UMR 1149, DHU UNITY, CRI, University Paris 7, Paris, France

$16{ }^{3}$ AP-HP, Pancreatology Department, Beaujon Hospital, Clichy, France

$17{ }^{4}$ AP-HP, Hepato-Gastroenterology and Nutrition Department, Hôpital Antoine-Béclère, 18 Clamart, France

19

20 Keywords: Enterococcus faecalis, alcoholic pancreatitis, intestinal microbiota, alcoholic

21 hepatitis 
Perrin et al. Cytolysin-positive Enterococcus faecalis is elevated in patients with chronic alcoholic pancreatitis

\section{ABSTRACT}

2 Introduction: Patients with alcoholic hepatitis have an increase in cytolysin-producing

3 Enterococcus faecalis that correlates with disease severity and mortality.

4 Aim: To determine whether patients with chronic alcoholic pancreatitis have an elevated 5 abundance of cytolysin-producing E. faecalis.

6 Methods: Quantification by qPCR of cytolysin-producing E. faecalis in controls and patients

7 with alcoholic hepatitis or pancreatitis.

8 Results: Patients with alcoholic pancreatitis had a higher proportion of intestinal cytolysin-

9 positive E. faecalis than healthy controls and patients with alcoholic hepatitis.

10 Conclusion: Cytolytic E. faecalis may also be involved in this other alcohol-related 11 complication and benefit from targeted microbiota editing strategies. 
Perrin et al. Cytolysin-positive Enterococcus faecalis is elevated in patients with chronic alcoholic pancreatitis

\section{INTRODUCTION}

Chronic, excessive alcohol consumption leads to several diseases, including alcoholic hepatitis ( $\mathrm{AH})$ and chronic alcoholic pancreatitis (CAP). These diseases are life-threatening complications of chronic alcohol consumption, with a high rate of mortality, and they have no specific treatment, except alcohol withdrawal. Several studies have shown that the intestinal microbiota plays a role in the pathogenesis of these two diseases and that patients with CAP or AH display altered and specific gut dysbiosis $(1,2)$. Among the differences observed in the intestinal microbiota, we previously reported a higher relative abundance of Enterococcus in patients with CAP (2).

A recent study by Duan et al. found that patients with $\mathrm{AH}$ have an elevated relative abundance of a particular type of fecal Enterococcus faecalis that produces a bacteriocin, cytolysin, which causes hepatocyte death. This bacteria is associated with more severe clinical outcomes and increase mortality in these patients (3). However, it was not clear in this study whether the alcoholic patients with alcoholic hepatitis that were included had any other alcohol-related complications. This could be of major interest, as the microbiome-editing strategy proposed by the authors could also be extended to other alcohol-induced complications if the relative abundance of this strain of Enterococcus faecalis is also elevated in such complications. We thus aimed to determine whether patients with chronic alcoholic pancreatitis also exhibit an elevated relative abundance of cytolysin-producing Enterococcus faecalis and compare their profile to that of patients with alcoholic hepatitis.

\section{METHODS}

Three groups of patients were included in the study: healthy controls $(\mathrm{HC})(\mathrm{n}=28)$, patients with $\mathrm{AH}$ and without $\mathrm{CAP}$ or acute pancreatitis $(\mathrm{n}=27)$ and patients with CAP and without $\mathrm{AH}(\mathrm{n}=24)$. Fecal samples were frozen at $-80^{\circ} \mathrm{C}$ and bacterial DNA was extracted as previously described (4). We amplified three bacterial genes: total bacterial 16S, E. faecalis $16 \mathrm{~S}$, and E. faecalis cytolysin $L\left(c y l L_{L}\right)$ (see Supplementary Material for details).

\section{RESULTS}

The patient characteristics are summarized in Table 1. We included patients with chronic alcohol consumption and two types of alcohol-related complications, $\mathrm{AH}$ without CAP and CAP without AH. Patients with CAP had a significantly higher abundance of fecal E. faecalis than healthy controls $(\mathrm{HC})(\mathrm{p}<0.0001)$ and AH patients $(\mathrm{p}=0.0004)$ (Figure 1A). 

available under aCC-BY-NC-ND 4.0 International license.

Perrin et al. Cytolysin-positive Enterococcus faecalis is elevated in patients with chronic alcoholic pancreatitis

1 There was no difference in the relative abundance of E. faecalis between $\mathrm{AH}$ patients and $\mathrm{HC}$

2 (Figure 1A). Genomic DNA of E. faecalis was detected in 96\% (23/24) of CAP patients, 89\%

$3(25 / 28)$ of $\mathrm{HC}(\mathrm{p}>0.05)$, and 85\% (23/27) of AH patients ( $\mathrm{p}>0.05)$ (Figure 1B). CAP

4 patients were more frequently cytolysin-positive $(23 / 24,96 \%)$ than $\mathrm{HC}(11 / 28,39 \%$, p <

$50.001)$ or AH patients $(13 / 27,48 \%, \mathrm{p}<0.001$, Figure 1C). In addition, the relative abundance

6 of cytolysin-positive E. faecalis was elevated in CAP and AH patients ( $\mathrm{p}=0.0006$ and $\mathrm{p}=$

7 0.0067) but not HC (Figure 1D). The relative abundance of cytolysin-positive E. faecalis did

8 not correlate with pancreatic disease severity, neither in terms of biological (inflammation and

9 albumin levels) nor radiological (necrosis and inflammation) severity criteria.

\section{DISCUSSION}

Overall, our data show that the relative abundance of cytolysin-positive E. faecalis is elevated in two different alcohol-related complications i.e. AH and CAP. Therefore, an increase in the relative abundance of cytolysin-positive E. faecalis is due to alcoholconsumption itself rather than to a specific complication. Toxicity of cytolytic E. faecalis against a human intestinal epithelial cell line has been shown (5) suggesting that it acts directly against the intestinal barrier. Moreover, studies in mice have shown that gut dysbiosis is involved in the pathogenesis of pancreatitis by inducing alterations in intestinal barrier function (6). Cytolysin levels increased significantly in the livers of mice given cytolytic $E$. faecalis, suggesting a direct toxic effect of cytolysin in the liver (3). Therefore, as alcohol itself increases gut permeability, the alcohol-related increase in cytolysin-positive E. faecalis in CAP may also be involved in the inflammatory process that leads to CAP. Accordingly, Enterococcus is the most common bacteria found in the bile of patients with CAP and antibodies against E. faecalis capsular polysaccharide are elevated in the blood of these patients (7). We therefore suggest that targeting cytolysin-positive E. faecalis using the bacteriophages described by Duan et al. could also be of great interest for CAP patients.

In summary, we confirm, in our independent French cohort, that patients with $\mathrm{AH}$ and no pancreatic complications have an elevated prevalence of cytolysin-positive E. faecalis and show that the prevalence of cytolysin-positive E. faecalis is also elevated in another alcoholrelated complication, CAP without alcoholic AH. This could be of great interest in battling this life-threatening complication, which has no specific treatment and which could benefit from the microbiota-editing strategy using targeted bacteriophages described by Duan et al 33 (3). Further studies are needed to confirm the role of cytolysin-positive E. faecalis in CAP and consider it as a therapeutic target in patients. 
Perrin et al. Cytolysin-positive Enterococcus faecalis is elevated in patients with chronic alcoholic pancreatitis

1 Guarantors of the article: Dragos Ciocan, $\mathrm{MD}, \mathrm{PhD}$ and Anne-Marie Cassard, $\mathrm{PhD}$.

2 Specific author contributions: CP: experimental design, acquisition, analysis, and

3 interpretation of data, and drafting of the manuscript. VR, CSV, DC, GP: patients'

4 recruitment. NT: technical support. GP, VR, AMC, DC: funding. AMC: data analysis and

5 interpretation, drafting of the manuscript. DC: study concept, data analysis and interpretation,

6 drafting of the manuscript. All authors have reviewed and approved the final draft of the

7 manuscript.

8 Acknowledgments. The authors thank the Plaimmo Platform, P. Serror (MICALIS,

9 UMT1319 INRA-AgroParisTech) for the generous gift of the E. faecalis DNA strain and C

10 Hugot for technical support.

Financial support: This work was supported by INSERM, Université Paris-Sud, the "Fondation pour la Recherche Médicale" (FRM), the National French Society of Gastroenterology (SNFGE), the "Association Française pour l'Etude du Foie" (AFEF), and the "Groupement Transversal INSERM sur le Microbiote" (GPT microbiota).

Potential competing interests: The authors declare to have no competing financial interests for the present work.

\section{REFERENCES}

1. Jandhyala SM, Madhulika A, Deepika G, Rao GV, Reddy DN, Subramanyam C, et al. Altered intestinal microbiota in patients with chronic pancreatitis: implications in diabetes and metabolic abnormalities. Sci Rep. 2017 Mar 3;7:43640.

2. Ciocan D, Rebours V, Voican CS, Wrzosek L, Puchois V, Cassard A-M, et al. Characterization of intestinal microbiota in alcoholic patients with and without alcoholic hepatitis or chronic alcoholic pancreatitis. Sci Rep. 2018 Mar 19;8(1):4822.

3. Duan Y, Llorente C, Lang S, Brandl K, Chu H, Jiang L, et al. Bacteriophage targeting of gut bacterium attenuates alcoholic liver disease. Nature. 2019;575(7783):505-11.

4. Ciocan D, Voican CS, Wrzosek L, Hugot C, Rainteau D, Humbert L, et al. Bile acid homeostasis and intestinal dysbiosis in alcoholic hepatitis. Aliment Pharmacol Ther. 2018 Nov;48(9):961-74.

5. Cox CR, Coburn PS, Gilmore MS. Enterococcal cytolysin: a novel two component peptide system that serves as a bacterial defense against eukaryotic and prokaryotic cells. Curr Protein Pept Sci. 2005 Feb;6(1):77-84. 
1 6. Chen J, Huang C, Wang J, Zhou H, Lu Y, Lou L, et al. Dysbiosis of intestinal microbiota and decrease in paneth cell antimicrobial peptide level during acute necrotizing pancreatitis in rats. PloS One. 2017;12(4):e0176583.

4 7. Maekawa T, Fukaya R, Takamatsu S, Itoyama S, Fukuoka T, Yamada M, et al. Possible involvement of Enterococcus infection in the pathogenesis of chronic pancreatitis and cancer. Biochem Biophys Res Commun. 2018 Dec 2;506(4):962-9. 
1 Table 1. Clinical characteristics of the three groups of patients.

\begin{tabular}{|c|c|c|c|}
\hline & $\begin{array}{l}\text { Chronic alcoholic } \\
\text { pancreatitis } \\
(\mathrm{CAP}, \mathrm{n}=\mathbf{2 4})\end{array}$ & $\begin{array}{c}\text { Severe alcoholic } \\
\text { hepatitis } \\
(\mathbf{A H}, \mathbf{n}=\mathbf{2 7})\end{array}$ & $\begin{array}{l}\text { Healthy controls } \\
(\mathrm{HC}, \mathrm{n}=\mathbf{2 8})\end{array}$ \\
\hline Age (years) $* * *$ & $51.4 \pm 9.8$ & $52.5 \pm 11.5$ & $34.9 \pm 11.6$ \\
\hline Sex $(\text { male/female })^{* * * *}$ & $21 / 3$ & $23 / 4$ & $12 / 16$ \\
\hline BMI $\left(\mathrm{kg} / \mathrm{m}^{2}\right)^{*}$ & $22.3 \pm 3.3$ & $26 \pm 5.2$ & $23 \pm 3.6$ \\
\hline Alcohol intake (g/day) * & $143.8 \pm 90$ & $106 \pm 65.5$ & \\
\hline Duration of intake (years)** & $13 \pm 3.9$ & $21 \pm 10.8$ & \\
\hline Smoking (\%) & $22(92)$ & $17(65)$ & \\
\hline Type 2 diabetes $(\%)$ ** & $10(42)$ & $2(8)$ & \\
\hline PPI use (\%) & $10(45)$ & $8(30)$ & \\
\hline $\mathrm{CRP}(\mathrm{mg} / \mathrm{L}) *$ & $37.4 \pm 72 . .1$ & $31.88 \pm 25 . .3$ & \\
\hline $\operatorname{AST}(\mathbf{U} / \mathbf{L})^{* * *}$ & $38 \pm 34 . .3$ & $242 \pm 495 . .7$ & \\
\hline $\operatorname{ALT}(\mathbf{U} / \mathbf{L})$ & $43.9 \pm 43 . .9$ & $66.4 \pm 88 . .4$ & \\
\hline Total bilirubin $(\mu \mathrm{mol} / \mathrm{L})^{* * * *}$ & $25 \pm 68$ & $210.5 \pm 172$ & \\
\hline GGT $(\mathbf{U} / \mathbf{L})^{* * *}$ & $182 . .9 \pm 287 . .9$ & $392.8 \pm 314 . .5$ & \\
\hline Glycaemia $(\mathrm{mmol} / \mathrm{L})^{* * *}$ & $7.3 \pm 1.9$ & $5.4 \pm 1$ & \\
\hline Serum albumin (mg/dL) & $31 \pm 7.8$ & $26.9 \pm 4,8$ & \\
\hline Platelets $\left(\times 10^{9} / \mathrm{L}\right)^{* * *}$ & $325 \pm 129$ & $109 \pm 88$ & \\
\hline Prothrombin time $(\%)^{* * *}$ & $94 \pm 13.9$ & $39 \pm 13.5$ & \\
\hline Cirrhosis $(\%)^{* * *}$ & 0 & $27(100)$ & \\
\hline Liver biopsy $(\%)^{* * *}$ & 0 & $27(100)$ & \\
\hline Maddrey score & & $55.9 \pm 21.3$ & \\
\hline MELD score & & $21.5 \pm 6.5$ & \\
\hline $\begin{array}{l}\text { Exocrine pancreatic } \\
\text { insufficiency }(\%)^{* *}\end{array}$ & $6(25)$ & 0 & \\
\hline \multicolumn{4}{|c|}{$\begin{array}{l}\text { Data is expressed as the mean } \pm \text { SD for continuous variables and } \mathrm{n}(\%) \text { for discrete variables. PPI: proton } \\
\text { pump inhibitors, CRP: C-reactive protein, AST: aspartate transaminase, ALT: alanine transaminase, GGT: } \\
\text { gamma-glutamyl transpeptidase, MELD: Model for End-Stage Liver Disease. }{ }^{*} \mathrm{p}<0.05, * * \mathrm{p}<0.01, * * * \\
\mathrm{p}<0.001\end{array}$} \\
\hline
\end{tabular}




\section{FIGURE LEGENDS}

\section{Figure 1. Fecal samples from CAP patients contain more $E$. faecalis and cytolysin than}

3 those of $\mathrm{AH}$ patients and HC. CAP: chronic alcoholic pancreatitis, AH: severe alcoholic

4 hepatitis, HC: healthy controls. (a) Fold change of E. faecalis relative abundance in fecal 5 samples from HC $(\mathrm{n}=28)$ and AH $(\mathrm{n}=27)$, and CAP patients $(\mathrm{n}=24)$, assessed by qPCR.

6 (b) Percentage of fecal samples positive for E. faecalis in $\mathrm{HC}(\mathrm{n}=28)$ and $\mathrm{AH}(\mathrm{n}=27)$ and

7 CAP patients $(n=24)$, assessed by qPCR. (c) Percentage of cytolysin positive fecal samples

8 in HC ( $\mathrm{n}=28)$ and $\mathrm{AH}(\mathrm{n}=27)$ and CAP patients $(\mathrm{n}=24)$, assessed by qPCR. (d) Relative

9 abundance of E. faecalis in fecal samples from AH and CAP patients and HC whose fecal 10 samples were cytolysin-positive or cytolysin-negative, assessed by qPCR. Data are shown as 11 the mean \pm SEM. Significant results for $* \mathrm{p}<0.05$, **p $<0.01$, and $* * * p<0.001$ were 12 determined by Mann-Whitney tests, unless stated otherwise. 
A
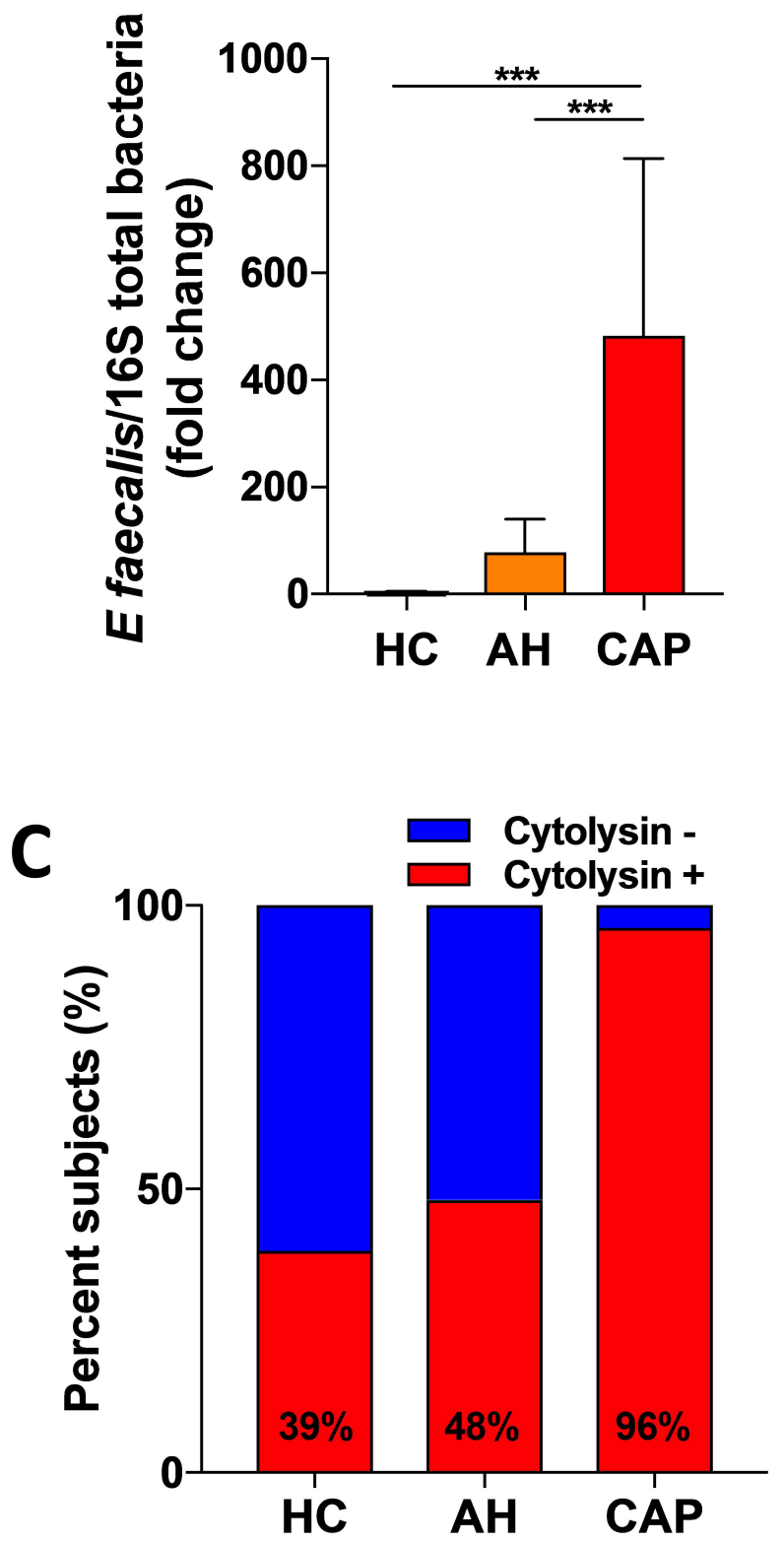

B
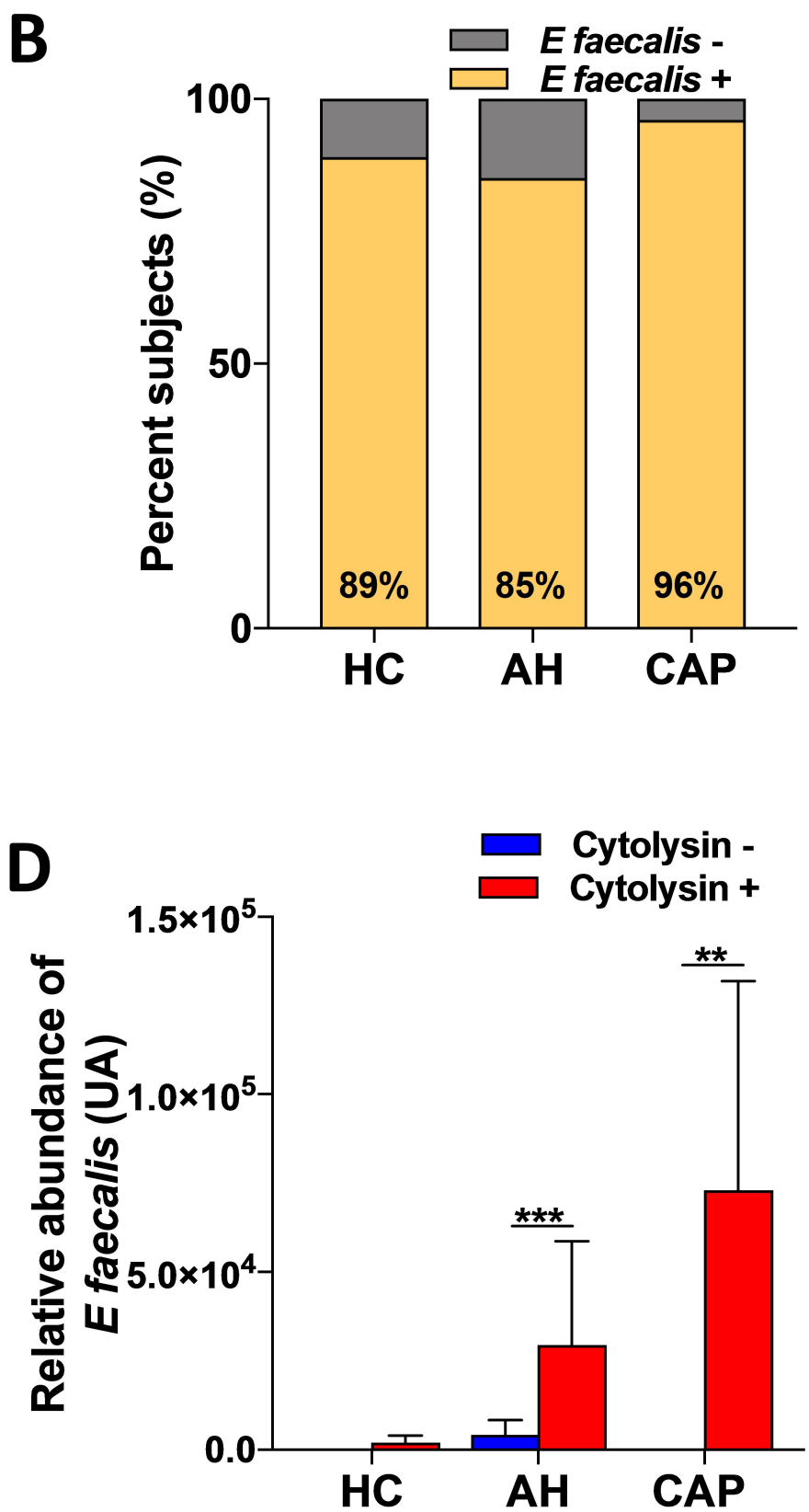